\title{
Zum Gedenken an Winfried Schrammek (1929-2017)
}

Am Samstag, dem 4. März 2017, ist Prof. Dr. Winfried Schrammek in seinem Haus an der Märchenwiese in Leipzig friedlich verschieden. Als Direktor des Museums für Musikinstrumente der Universität Leipzig hat er nach der friedlichen Revolution eine wichtige Rolle bei der Neuorganisation der Musikwissenschaft in Leipzig gespielt. Bis zuletzt war der 87-Jährige aktiv und engagiert vor allem als Orgelforscher über das Leipziger Musikleben hinaus tätig.

1929 in Breslau geboren, besuchte er das Herzog-Friedland-Gymnasium in Sagan und erlangte das Abitur nach Kriegsdienst und Vertreibung 1948 in Jena. Hier studierte er (nach einer Kirchenmusikausbildung in Weimar) an der Universität Musikwissenschaft, Germanistik und Völkerkunde. 1956 wurde er von Heinrich Besseler mit einer Arbeit über das Buxheimer Orgelbuch promoviert. Als wissenschaftlicher Mitarbeiter arbeitete er zunächst an der Musikabteilung am Institut für Volkskunstforschung in Leipzig, anschließend ab 1962 am Leipziger Musikinstrumentenmuseum. Nach fünfzehn Jahren wissenschaftlicher Tätigkeit stieg er zum Kustos der Sammlung auf, in der Umbruchszeit wurde er - politisch vollkommen unbelastet - 1988 zum kommissarischen Leiter und 1989 zum Direktor des Museums berufen. Mit großem Geschick verstand er es, in vertrauensvoller Zusammenarbeit mit der Universitätsverwaltung und ihrer Leitung die kulturellen Anliegen seines Hauses sowie die persönlichen Schicksale seiner Mitarbeiter erfolgreich zu vertreten, so dass alle Arbeitsplätze erhalten und die vielfältigen Aktivitäten des Museum fortgesetzt werden konnten. Mit starkem Verantwortungsbewusstsein setzte er sich stets für seine Mitarbeiter ein und ermöglichte ihnen die Entfaltung ihrer Interessen, so dass eine harmonische und ertragreiche Arbeitsatmosphäre entstehen konnte.

Zahllose Sonderausstellungen zeichneten seine lebendig ausstrahlende Direktionszeit am Musikinstrumentenmuseum aus, an denen er immer wieder als ausgewiesener Spezialist für die Orgel und andere Tasteninstrumente beteiligt war. In seinen eigenen Publikationen wie dem zusammen mit Hubert Henkel und Klaus Gernhardt 1983 herausgebrachten Museumskatalog Orgelinstrumente, Harmoniums widmete Schrammek sich seiner Thematik unter ganz verschiedenen Aspekten, es ging ihm nicht nur um bautechnische Angelegenheiten, sondern in einem viel umfassenderen Sinne um die Aufführungspraxis und um die liturgische Sinngebung der Instrumente und ihrer Musik. Als Orgelsachverständiger war er bei der Rettung und Restaurierung vieler Orgeln der Region tätig, darunter zweimal für die Silbermannorgel der Dresdner Hofkirche, und erwarb sich mit klarem Sachurteil den großen Respekt von Orgelbauern und Organisten. Zuletzt konnte er diese wunderbare Gabe segensreich in die Arbeit der Rektoratskommission „Orgel für den Neubau der Aula/Kirche am Campus Augustusplatz“ der Universität Leipzig einbringen. Das Ergebnis trägt wesentlich auch seine Handschrift, mit großer Freude konnte er die Fertigstellung der großen JehmlichOrgel und des ersten Bauabschnitts der Metzler'schen Schwalbennestorgel noch erleben und die Orgeln selbst spielen. 